\section{Chemoport anchoring - the in situ technique}

\author{
Krishnamachar Harish, Yagachikatte \\ Chikkanarasaiah Madhu \\ Department of Surgical Oncology, M.S. \\ Ramaiah Curie Center of Oncology, M.S. \\ Ramaiah Medical College, Bangalore, \\ India
}

\section{Abstract}

Chemoports are subcutaneously placed long term central venous access devices usually inserted under local anaesthesia. Rare complications include port inversion or flip over. These can be prevented by anchoring the port to the tissues at its base. We describe an insitu technique of port anchoring. Here, the port is first 'fixed' temporarily to the overlying skin by Huber needle, thus facilitating placement of fixing sutures without port manipulation. The described technique is safe and we have not encountered complications. In addition, explanting the port was easier due to the use of delayed absorbable sutures. It is safer to anchor the port even if the port pocket ensures that the port fits in snugly. This described technique results in minimal manipulation of portcatheter system thereby ensuring that the catheter tip which is properly placed remains unaltered.

\section{Introduction}

Subcutaneously placed totally implantable central venous devices were first introduced in the early 80 's. ${ }^{1}$ Over the years, they have almost replaced the external catheters when long term intermittent venous access is required. The venous access could be either by percutaneous technique or by venous cut down through subclavian or internal jugular vein approach. ${ }^{2}$ Venous access devices are usually inserted under local anaesthesia. The vein is accessed with a needle guide wire (Seldinger) in the percuatneous technique followed by the dilator and sheath introduction over the guide wire. The guide wire and dilator are then withdrawn, followed by insertion of the catheter which is then tunneled and brought out through the wound created for placement of the reservoir. The catheter tip is then positioned appropriately at the superior venacava and atrial junction. The other end is then fixed to the reservoir which is then placed in the pocket specially created for that. Alternatively, in a prefixed port-catheter, the tip is cut earlier to a pre-measured distance and then the port is placed in the reservoir pocket made for that purpose. The reservoir-port is then anchored in the pocket. This is done to avoid a flip or rotation of port in the pocket as well as migration. Stitches over the fascia are taken separately in pre-identified areas; the same are then threaded over the port and these sutures with long lengths of thread are then cut. The thread placement over the port is done outside the wound; the port is then guided over the thread into the pocket and the threads are tied. In this technique some length of catheter is withdrawn during suturing of the port and manipulated to fit into the pocket. This length of catheter withdrawal could be 2 to $3 \mathrm{~cm}$. Although it can be usually pushed back, sometimes the catheter cannot be easily pushed and could result in kinks. There would be difficulty in free flow of fluid and further cuts in the length of catheter to overcome this kink would result in tip of catheter being placed at a position other than the one desired and planned. To overcome this problem, an in situ technique of port anchoring is described in which the port can be placed accurately and fixed in the same place without disturbing the position.

\section{Methods and technique}

A small pocket is created to accommodate the port. The incision should be slightly longer than the width of the port (Figure 1). The pocket is then created by blunt and sharp dissection in the subcutaneous plane. Cautery may be used to obtain hemostasis. The pocket should be deep enough to place the port access site at least 1.5-2 $\mathrm{cm}$ away from the incision site. The width of the pocket should be just adequate to allow placement of port. The main idea is to ensure that there is no vacant or dead space which would allow serous/blood collection to occur resulting in infection later. In addition, wider pocket would allow movement and dislodgement of the port.

Anchoring of the port to the underlying fascia is a difficult task if the port is already in place in a small cavity. We describe a technique of anchoring the port which has been followed for all our 143 procedures over the last 3 years (2008-2010). Once the pocket is created, the port is placed inside to check the size and depth of the pocket. Once the created pocket is found to be satisfactory, the port is removed and flushed with heparinized saline. The catheter tip is then positioned accurately and the other end is brought out through the tunnel and cut at appropriate length. The catheter is then advanced over the port stem and the lock advanced to stay flush with the port (Figure 2). The port is then placed in the correct position inside the pocket. Gentle push of the port into the pocket and gentle pull of
Correspondence: Harish K, 2866, 13TH Main ' $\mathrm{E}$ ' Block, Subramanyanagar, Bangalore - 560010, India. Tel: +91.080 .23608888$

E-mail: drkhari@yahoo.com

Key words: totally implantable central venous device, subclavian vein, internal jugular vein, flip over, inversion.

Contributions: $\mathrm{KH}$, performed surgeries, devised the technique and standardized it. Contribution in concept, design, drafting of manuscript and reference search; MYC, case assistance, revision of draft manuscript.

Conflict of interest: the authors report no conflicts of interest.

Received for publication: 30 June 2011. Accepted for publication: 4 August 2011.

This work is licensed under a Creative Commons Attribution NonCommercial 3.0 License (CC BYNC 3.0)

(C) Copyright K. Harish and Y.C. Madhu., 2011 Licensee PAGEPress, Italy

Surgical Techniques Development 2011; 1:e9 doi:10.4081/std.2011.e9

the skin simultaneously ensures that there is no dead space in the distal pocket (Figure 3). In this position, a straight or right angled Huber needle with syringe containing heparinized saline is used to pierce the port septum through the skin (Figure 4). The piston of the syringe is gently withdrawn. This results in blood being aspirated into the syringe and confirms the catheter placement in the vein without any obstruction to flow of blood or fluids. The port is then flushed with heparinized saline. The syringe is then removed leaving the needle in place. This needle 'fixes' the port to the skin. This ensures that there are limited movements in the all axis. There could be some movements in the 'Y' axis but these are rotational movements and they are limited because of the small pocket. In addition, there could be some movements in the ' $\mathrm{Z}$ ' axis but this again is with skin. Limited movements in these axes help us to anchor the port in the pocket where there is very small area to place the stitch. One or two small retractors are then placed to visualize the port. The base of the port where anchoring stitch is to be applied is identified. The port is then turned over partly in the ' $\mathrm{Z}$ ' axis, the stitch applied over the fascia and into the eye of the port (Figure 5A,B). The stitch is then tied. The same maneuver is done for the other eye of the port (Figure 5C). We have used 3'0' vicryl for anchoring all our port implants. Once the anchoring stitches are well placed, the Huber needle is removed and the skin closed after a gentle tug to the port-catheter system to 
check the anchoring. The distance of port access from skin suture line remains same as that of the initial needle puncture used for fixing the port to the skin.

\section{Results}

This technique has been followed in all the 143 ports placed at our institution. No difficulties were encountered in placing sutures with port in situ. There were no damages to port or to the needle or to the skin while placing sutures. There were no injuries to the catheter

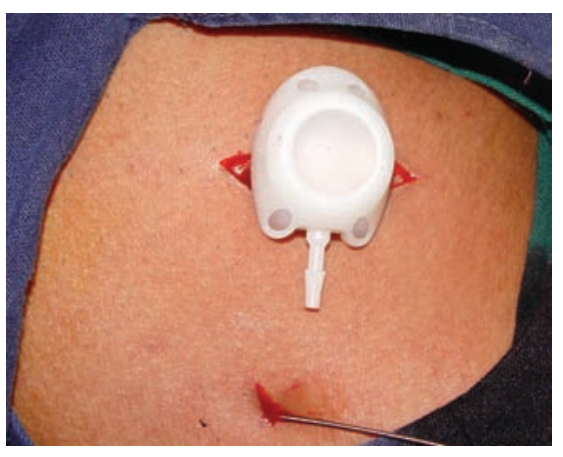

Figure 1. Port placed over the incision showing the incision slightly larger than the port width to snugly accommodate port.

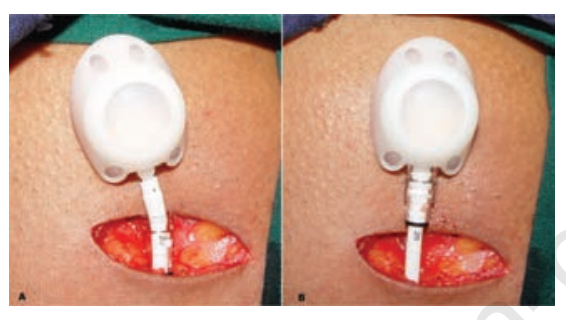

Figure 2. A) The catheter is advanced over the port stem beyond the barb; B) The catheter lock is advanced over the catheter onto the port stem; flush with the port.

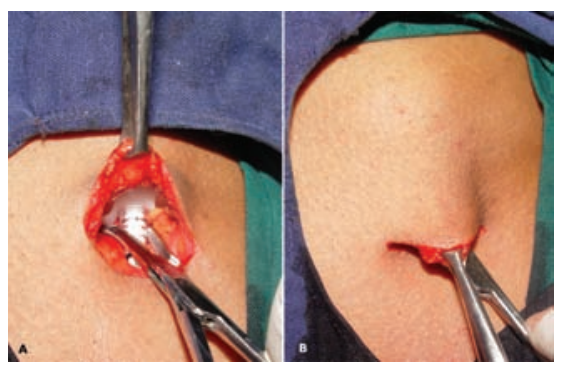

Figure 3. A) The port is being pushed with an open haemostat; B) The Allis forceps is used to grasp the dermis and subcutaneous tissues and pull over the port simultaneously. The haemostat is NOT grasping any part of the port catheter system but is used only to push the port deep into the pocket. while placing the sutures since the catheter is far from the suture area and the thick catheter lock is adjacent to the port eye where the sutures are placed. Ports were retained for an average period of 12-18 months before they were explanted. One patient had the port explanted at $7^{\text {th }}$ day due to acute infection. 17 patients had ports explanted between 4-6 months due to infection. 28 patients died between 6-12 months with port in place. 5 patients were lost on follow up. There has been no instance of port migration or flip over. No complications were noted because of the suture material. In addition, whenever the port was explanted, it was easier to enucleate once the pseudo capsule was entered as these sutures were by then absorbed.

\section{Discussion}

Traditionally, the port is anchored to the tissues at its base which ensures stability and fixes the port in that place. ${ }^{2,3}$ However, some authors feel that when the port is placed snugly in the pocket, fixing of port is not routinely required..$^{4-6}$ There are others who have anchored the port if the pocket was large or when there was a complication of flip over or rotation. ${ }^{7,8}$ The suturing was avoided to pre-

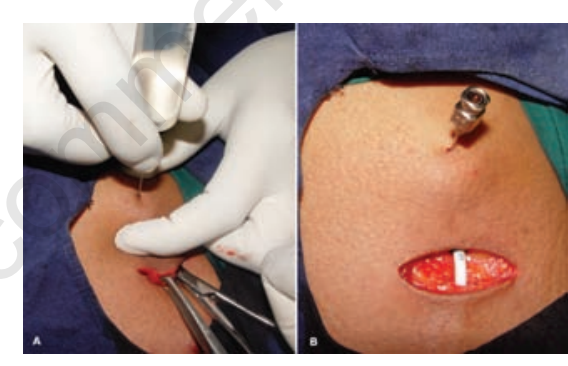

Figure 4. A) The assistant feels the port and inserts the Huber needle with syringe; B) The needle is left in place while syringe is removed. Note the distance between the puncture for port access (the Huber needle) and the skin incision. In the described in situ technique, this distance remains constant and does not change later.

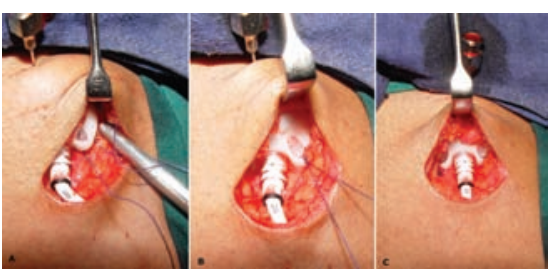

Figure 5. A) Suture being placed while port is in situ; B) Completed suture on one side C) and the other. Note the retrograde flow of blood/heparinized saline which can occur occasionally. vent infection and to lessen the operative time. Both these arguments are no longer tenable and hence some have switched over to fixing the port. ${ }^{9}$ Port inversion or flip over is rare but described complication. Manipulation of the port by the patient intentionally or unintentionally (similar to rotation of pacemaker) is described as twiddler's syndrome. ${ }^{10}$ One, two or three cases of such port inversions has been reported in various series. ${ }^{7-9,11}$ The axis of rotation is defined by the port and catheter stem rotating the septum sideways or upside down over the chest wall. These were due to non placement of anchoring sutures or breakage of the same. ${ }^{2}$ We however, routinely anchor the ports in the pocket.

Conventionally non-absorbable sutures are used for anchoring. ${ }^{2}$ We however use 3 ' 0 ' Vicryl ${ }^{\circledR}$ (Ethicon Vicryl, Johnson \& Johnson, Somerville, NJ, USA) for anchoring the port as practiced by some authors. ${ }^{8}$ The advantage of this is that it is delayed absorbable. It ensures that the port is relatively immobile for about 810 weeks (time for losing tensile strength and absorption). By that time, the surrounding tissues would have formed a good pseudo-capsule which would prevent any mobility. Another advantage of this suture is during port removal. We have encountered some difficulties when we have explanted ports implanted by others and fixed with non-absorbable sutures. In our experience, the removal of ports fixed with Vicryl ${ }^{\circledR}$ would be easy since the sutures would by then be absorbed. Entry into pseudo-capsule would facilitate easy enucleation of the port. Experimentally, suture fixation was found superior to glue or self stabilization in rabbits. ${ }^{12}$

The technique described for port anchoring uses the Huber needle inserted into the port for fixing the port to skin. This limits the movements and mobility of the port during anchoring while at the same time it allows limited manipulation to facilitate placement of sutures. The technique of pushing the port deep into the pocket eliminates distal dead space. In addition, it ensures that we obtain maximum distance between the suture line and the puncture site of the port septum.

Sometimes, small amount of retrograde flow and extravasation of heparinzed saline or blood in the Huber needle can occur (Figure 5C). This retrograde flow does not result in any major complication. Only two areas of suturing of port to underlying tissues are required and it takes a few minutes. We have not encountered thrombosis, as the needle is removed once the anchoring is complete; a final check and flush with heparinized saline is done at the end of the procedure. In addition, this back flow can be prevented by continuing to have the syringe attached to the needle. We find that cumbersome and unnecessary; hence we remove the syringe from the needle. 
The port is anchored to tissues after positioning the catheter tip under guidance. Manipulation of the port afterwards for anchoring displaces the tip from its intended position. The main advantage of this in situ technique is that it makes handling and manipulation of port-catheter system minimal. This ensures that the tip of the catheter placed under radiologic guidance does not get altered and stays in the same place. Another advantage is that the skin suture line and port access site are defined and could be altered (by making a deeper pocket) if required before anchoring. One additional practice at our institution is to administer the chemotherapy on the same day as port insertion. The beneficial side effect of this practice is that the port is 'fixed and immobile' at least for the initial 6-10 hours.

\section{References}

1. Niederhuber JE, Ensminger W, Gyves JW, et al. Totally implanted venous and arterial access system to replace external catheters in cancer treatment. Surgery 1982;92:706-12.

2. Whitman ED. Complications associated with the use of central venous access devices. Curr Probl Surg 1996;33:309-78.

3. Ignatov A, Hoffman 0, Smith B, et al. An 11-year retrospective study of totally implanted central venous access ports: complications and patient satisfaction. Eur J Surg Oncol 2009;35:241-6.

4. Mauro MA, Jaques PF. Radiologic placement of long-term central venous catheters: a review. J Vasc Interv Radiol 1993;4:127-37.

5. Simpson KR, Hovsepian DM, Picus D. Interventional radiologic placement of chest wall ports: results and complications in 161 consecutive placements. J Vasc Interv Radiol 1997;8:189-95.

6. Charles HW, Miguel T, Kovacs S, et al. Chest port placement with use of the single-incision insertion technique. J Vasc Interv Radiol 2009;20:1464-9.

7. Diaz ML, Villanueva A, Herraiz MJ, et al. Computed tomographic appearance of chest ports and catheters: a pictorial review for noninterventional radiologists.
Curr Probl Diagn Radiol 2009;38:99-110.

8. Cil BE, Canyigit M, Peynircioglu B, et al. Subcutaneous venous port implantation in adult patients: a single center experience. Diagn Interv Radiol 2006;12:93-8.

9. Rodgers HC, Liddle K, Nixon SJ, et al. Totally implantable venous access devices in cystic fibrosis: complications and patients' opinions. Eur Respir J 1998;12:217-20.

10. Gebarski SS, Gebarski KS. Chemotherapy port "Twiddler's syndrome". A need for preinjection radiography. Cancer 1984;54: 38-9.

11. Yeste Sanchez L, Galbis Garavajal JM, Fuster Diana CA, Moledo Eiras E. Protocol for the implantation of a venous access device (Port-A-Cath System). The complications and solutions found in 560 cases. Clin Transl Oncol 2006;8:735-41.

12. Na HI, Shim HJ, Kwak BK, et al. Fixation methods for implantable port chamber: comparative study using glue, self-stabilizing leg and suture fixations in rabbits. Korean J Radiol 2004;5:266-73. 